\title{
From movement into action to manner of causation: changes in argument mapping in the into-causative
}

Flach, Susanne

\begin{abstract}
Over the last 300 years, the into-causative (he talked his father into giving him money) increased in frequency and lexical diversity. Changes of this kind are often taken as evidence of functional expansion. From a Construction Grammar $(\mathrm{CxG})$ perspective, this paper argues that what appears to be a loss of restrictions on the verbal slot results from changes in argument mapping links. As the construction provides the argument roles by mapping semantics (causer, causee, result) onto syntax (subject, object, oblique), stronger mapping links increasingly facilitated the use of verbs that are semantically and syntactically atypical for the expression of causation. Data from the Corpus of Historical American English confirm three predictions of this hypothesis with respect to shifts in (i) the semantic classes of matrix verbs, (ii) their general argument structure preferences, and (iii) voice-marking. The results provide evidence for a subtle semantic change from movement into action to manner of causation. The increase in frequency and productivity are hence explained as the consequence of the syntactic form becoming a more reliable cue for causative meaning. We discuss implications for models of language change against the background of current issues in Diachronic Construction Grammar (DCxG) pertaining to constructionalization vs. constructional change.
\end{abstract}

DOI: https://doi.org/10.1515/ling-2020-0269

Posted at the Zurich Open Repository and Archive, University of Zurich

ZORA URL: https://doi.org/10.5167/uzh-198077

Journal Article

Published Version

The following work is licensed under a Publisher License.

Originally published at:

Flach, Susanne (2021). From movement into action to manner of causation: changes in argument mapping in the into-causative. Linguistics, 59(1):247-283.

DOI: https://doi.org/10.1515/ling-2020-0269 


\title{
Susanne Flach*
}

\section{From movement into action to manner of causation: changes in argument mapping in the into-causative}

https://doi.org/10.1515/ling-2020-0269

Received December 15, 2020; accepted December 15, 2020

\begin{abstract}
Over the last 300 years, the into-causative (he talked his father into giving him money) increased in frequency and lexical diversity. Changes of this kind are often taken as evidence of functional expansion. From a Construction Grammar $(\mathrm{CxG})$ perspective, this paper argues that what appears to be a loss of restrictions on the verbal slot results from changes in argument mapping links. As the construction provides the argument roles by mapping semantics (causer, causee, result) onto syntax (subject, object, oblique), stronger mapping links increasingly facilitated the use of verbs that are semantically and syntactically atypical for the expression of causation. Data from the Corpus of Historical American English confirm three predictions of this hypothesis with respect to shifts in (i) the semantic classes of matrix verbs, (ii) their general argument structure preferences, and (iii) voice-marking. The results provide evidence for a subtle semantic change from movement into action to manner of causation. The increase in frequency and productivity are hence explained as the consequence of the syntactic form becoming a more reliable cue for causative meaning. We discuss implications for models of language change against the background of current issues in Diachronic Construction Grammar (DCxG) pertaining to constructionalization vs. constructional change.
\end{abstract}

Keywords: argument mapping; argument structure constructions; association plots; constructional change; constructionalization; corpus linguistics; Diachronic Construction Grammar; into-causative

\section{Introduction}

When constructions increase in frequency, an intuitive explanation is that they have expanded in semantic and/or functional scope, particularly if the rise is

*Corresponding author: Susanne Flach, Englisches Seminar, Universität Zürich, Plattenstrasse 47, 8032 Zürich, Switzerland, E-mail: susanne.flach@es.uzh.ch. https://orcid.org/0000-00027469-2703 
accompanied by changes in the lexical material that can occur in the construction. For example, more attested verbs in an open slot may indicate that a construction imposes fewer constraints on that slot. With fewer restrictions and a wider range of possible verbs, a construction becomes available in more discourse-pragmatic contexts and subsequently increases in usage.

Functional extension is also a plausible explanation for the steep rise of the into-causative (Mary talked John into signing the contract). In this construction, a causer acts upon a causee such that the causee carries out the action in the intocomplement. Several synchronic properties have motivated an analysis in Goldbergian Construction Grammar (CxG) (e.g., Rudanko 2011; Stefanowitsch 2014). Most generally, CxG attributes the causative meaning to the syntactic form [SUBJ V OBJ into V-ing], while the matrix verb specifies how the causation is brought about, even if the verb itself is not causative (i.e., by talking).

This article takes a Diachronic CxG (DCxG) perspective to account for the construction's recent developments. Following its emergence in the 17th century from a series of changes in the caused-motion construction (He put the army into France; God put man into doubting; cf. Flach 2020), the into-causative has remained formally and semantically stable, licensing the same types of verbs that characterize its contemporary use. On the other hand, it rose more than five-fold in frequency over the last 200 years and increased in lexical diversity (cf. Section 3; Davies and Kim 2019). These quantitative changes, which suggest a non-trivial qualitative change, have led to proposals that the construction expanded functionally and became 'more neutral' or 'indirect' with regard to the force of causation (Davies and Kim 2019; Rudanko 2005, 2006).

This paper attempts to account for the changes from a constructionist perspective: rather than undergoing functional expansion, the into-causative has become more idiosyncratic in its expression of causative meaning. The logic is as follows: Goldberg's (1995) classic version of CxG assumes that an argument structure construction, e.g., [SUBJ V OBJ OBL], provides the argument roles and maps semantics onto syntax (causer-SUBJ, causee-OBJ, result-OBLIQUE). This mapping comes in the form of vertical links between argument roles (syntax) and participant roles (semantics). This implies that the strength of the links correlates with constructional idiosyncracy: the stronger the links, the greater a construction's ability to contribute to the meaning of an expression, and hence the greater the construction's tolerance to license less compatible lexical material.

This article applies these assumptions to the diachronic context in order to account for the quantitative changes. The hypothesis is that the construction's rise is a result of progressively stronger vertical links. As these become stronger, the into-causative is more likely to license verbs that are semantically or syntactically incompatible with constructional semantics. In other words, the syntactic form of 
the into-causative may have become a more reliable cue for causative meaning, increasingly independent of verb semantics and their subcategorization preferences. Crucially, this does not necessarily entail functional-pragmatic expansion of the construction.

These hypotheses will be explored using data from the Corpus of Historical American English (COHA). Three case studies track the distributional changes in the semantic classes of the matrix verbs (e.g., force, communication verbs), their argument structure preferences (i.e., transitivity), and voice-marking (passive, active). The data show that material which is compatible with constructional semantics was initially overrepresented, while incompatible material gained ground only over time. As an abstract characterization of its semantic development, the into-causative subtly changed from profiling movement into action to specifying manner of causation.

The article aims to make two major contributions. First, it explores the possibility that changes in frequency and/or lexical variability are indicators of change in the strength of links. Second, it discusses the results within a larger Diachronic Construction Grammar $(\mathrm{DCxG})$ context. As research in language change increasingly embraces constructionist ideas, this article seeks to contribute to the debate on the relationship between constructionalization, i.e., the creation of new constructions, and constructional change(s), i.e., the change within constructions. To this end, Section 2 discusses the basic tenets of $\mathrm{CxG}$ and the historical background of the into-causative. Section 3 describes the data set, which is analyzed in three case studies in Section 4. Section 5 discusses the implications for models of language change.

\section{Background}

\subsection{The into-causative in a Construction Grammar perspective}

The into-causative encodes events where a cause(r) prompts a causee to perform the activity encoded in the into-complement:

(1) a. A friend of mine bought a similar machine, may be better than mine, for \$90. They tricked me into buying the machine for \$186 on credit.

(COHA, NF, 1971)

b. As I said, she's a convincer. A talker. She can talk people into doing almost anything she wants them to.

(COHA, FIC, 1961) 
c. Microsoft appears to use a software industry trade association to cheat, bullying foreign companies into buying only Microsoft products.

(COHA, MAG, 1998)

d. Lawmakers wanted to pressure schools into bringing test scores of poor and minority children up to the level of their affluent white peers.

(COHA, NEWS, 2006)

e. Let us pray that his love and mercy will comfort the bereaved, heal the injured, and help and guide leaders into taking decisions that will avoid more suffering to humankind.

(COHA, MAG, 2001)

f. I will not sphroxify gullible people into looking up fictitious words in the dictionary.

(COHA, NEWS, 1997)

The basic constructional meaning is ' $X$ CAUSES Y TO DO Z', syntactically expressed in two clauses. The matrix clause encodes the cause event (they tricked me), while the complement clause encodes the result event (I buy the machine). The into-causative exhibits object-control: the object of the matrix clause-e.g., me in (a)-is the understood subject of the complement clause, because its referent (me) performs the action in the -ing clause (buy the machine). This separates the into-causative from subject-control patterns of the same syntagmatic form (Mary put energy into completing the project). These are not into-causatives under this definition, because the subject referent Mary completes the project, not the object referent energy. ${ }^{1}$

A Construction Grammar $(\mathrm{CxG})$ framework is particularly suited for the analysis of the into-causative. $\mathrm{CxG}$ assumes that constructions are form-meaning pairs and that the schematic form contributes to the meaning of an expression. This accounts for properties that are unpredictable from either the form of the construction or the elements in its slots (Goldberg 1995: 4). Therefore, the causative meaning in (1) is

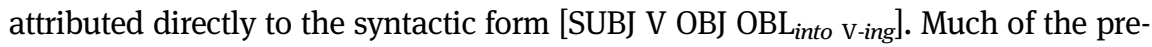
vious literature on the into-causative makes explicit reference to $\mathrm{CxG}$ (e.g., Rudanko 2006, 2011; Stefanowitsch 2014), which is warranted for three reasons.

First, the causative meaning is independent of the verbs in the matrix clause. Most verbs, if not all, are neither causative nor typical three-participant verbs. For instance, talk, the most frequent verb, is unacceptable with animate objects outside the construction ( ${ }^{*}$ She talks people). It is conventional only in intransitives (She talks), complex intransitives (She talks to people), or with inanimate themes (She talks

1 Passives have subject-control ( $\mathrm{He}_{\mathrm{i}}$ was talked into (him $\left.\mathrm{i}\right)$ signing the contract), so it might be more suitable to speak of patient-control. The point is not important here: unlike other argument structure constructions, all passive into-causative uses have active paraphrases (and vice versa). 
business). Conversely, the construction does not license verbs that express its constructional meaning, most notably cause and make (Stefanowitsch 2014: 224). This is in contrast to the ditransitive, for example, where the typical verbs all express the notion of transfer (e.g., give, tell, send, or offer; Stefanowitsch and Gries 2003: 229).

Thus, causative meaning cannot be contributed by the verbs, unless we posit 'implausible verb senses' of causation (Goldberg 1995: 9). Rather, the verbs in the into-causative specify the manner of causation, in contrast to make- or get-causatives (Gilquin 2010; Stefanowitsch 2001). A more specific characterization of the into-causative would thus be 'X CAUSES Y TO DO Z by means of V'. Note also that the construction has a distinct resultative effect: they pressured him into signing the deal entails that the signing took place, while accomplishment is not necessarily implied in they pressured him to sign the deal (Rudanko 2011: 13-16, 2006: 316). In other words, the into-causative is inherently telic: while the entailment of accomplishment largely depends on the verb in infinitival to-complements, it is part of the constructional meaning of the into-causative (Rudanko 2011: 13).

The construction's high type-token ratio has led many to ask if and how speaker creativity is limited (Davies and Kim 2019; Hunston and Francis 2000; Kim and Davies 2016; Rickman and Kaunisto 2018; Rudanko 2005, 2006; for analyses across varieties, cf. Brunner (2019) and Wulff et al. (2007)). However, this is productivity within semantic classes (e.g., Gries and Stefanowitsch 2004; Stefanowitsch 2014; Stefanowitsch and Gries 2003): the majority of types and tokens are verbs of trickery or deception (cheat, con, deceive, fool), communication or persuasion (cajole, coax, sweet-talk, wheedle), fear or irritation (bully, frighten, intimidate, scare), and force (brainwash, pressure, strong-arm, torture). The remaining types are manner-unspecific verbs of low token frequencies in the intocausative (drive, guide, lead, motivate, stimulate).

Second, a CxG analysis accounts for these properties by assuming that the construction maps the participant roles causer, causee, and result (semantics) onto the argument roles subject, object, and oblique (syntax), respectively. Figure 1 shows a classic $\mathrm{CxG}$ representation, with the mapping links represented as arrows.

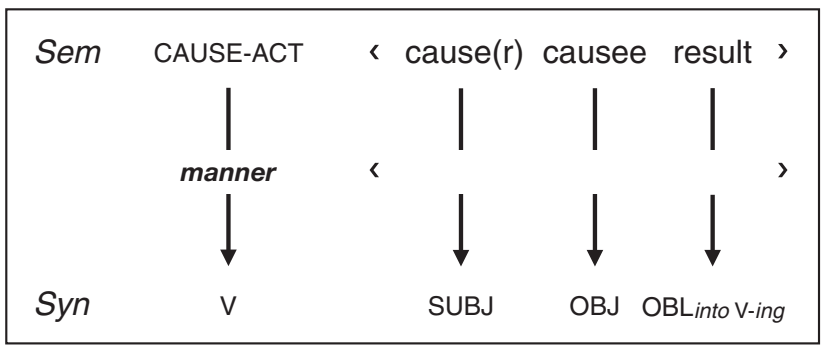

Figure 1: The into-causative in CxG (adapted from Stefanowitsch 2014: 220). 
The vertical links between syntax and semantics explain why the construction licenses verbs that are neither causative nor typical three-argument verbs-this property is contributed by the construction itself. Nevertheless, the construction has a tendency to attract verbs that have an implied effect for action: to bully, pester, scare, or intimidate suggests that causees are affected such that they feel compelled to act. Similar implied effects are absent from verbs of transformation and path-creation, such as throw (thrower, throwee, location thrown into). They are, as a class, not incompatible with the meaning of causation (cf. their high prevalence in the caused-motion construction), but they are very rare in the intocausative; some attested verbs include the force verbs push, drag, and kick. Therefore, like most open-slot constructions, the into-causative is not an 'anythinggoes construction' of unconstrained creativity. Its lexical diversity is chiefly diversity within the main classes that are compatible with constructional semantics via an implied causative effect.

The third motivation for the $\mathrm{CxG}$ analysis is based on its close relationship with other argument structure constructions, most notably the caused-motion construction as in he ushered her into the room (Rudanko 2011; Figure 2). Both its form [SUBJ V OBJ OBL $\mathrm{PP}_{\mathrm{P}}$ ] and its basic meaning ' $\mathrm{X}$ CAUSES $Y$ TO MOVE $Z$ ' are very similar to the intocausative ([SUBJ V OBJ into V-ing], 'X CAUSES Y TO Do Z'). The goal arguments in both constructions encode (metaphorical) movement along a path, which is verbal in the into-causative (into V-ing), but nominal in the caused-motion construction (into NP).

Yet, the into-causative is both more complex and more specific. First, the construction is bi-clausal, i.e., syntactically more complex. Second, the verbs in the into-causative are restricted to a few semantically specific classes. Third, following from object-control, the causee is always animate or construed as animate (cf. schools in 1d). Fourth, although trivial, it only features one directional preposition (into). Fifth, the goal is always metaphorical movement into a state of action ('Do Z') rather than more generally into a container ('MOVE Z'). As none of

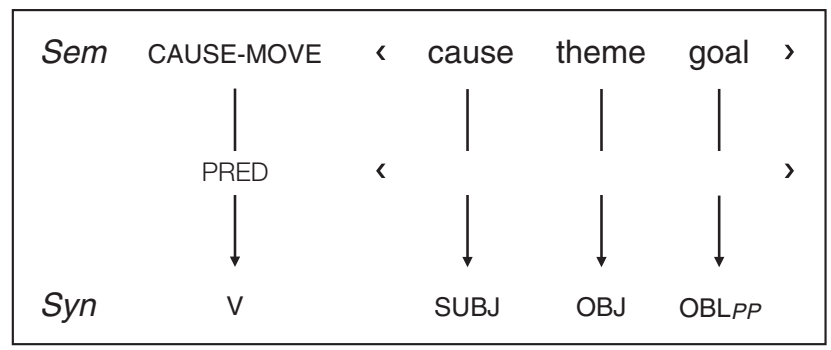

Figure 2: The caused-motion construction in CxG (based on Goldberg 1995: 78). 
these properties are predictable from the caused-motion construction, postulating a separate construction is warranted on analytical grounds (Goldberg 1995: 4).

An additional semantic property that is relevant to the diachronic discussion has recently received some attention. On the one hand, the construction implies negativity, manipulation, and reluctance on the part of the causee (Gries and Stefanowitsch 2004; Hunston and Francis 2000; Rudanko 2011; Stefanowitsch and Gries 2003; Wierzbicka 1998; Wulff et al. 2007). On the other hand, the intocausative also occurs in neutral or even positive contexts with verbs such as guide, lead, encourage, or motivate (Kim and Davies 2016). The absence of negativity or reluctance has been argued to speak against its status as a construction in the $\mathrm{CxG}$ sense (Duffley 2018):

It would be nice to know about the athletes at other times of the year. It will also guide kids into reading other things they find in the newspaper.

(COCA, 2000)

Duffley's position would be plausible if these properties were necessary conditions for a constructional status. Two arguments can be put forth in response. First, 'neutral' or 'positive' contexts expressed by guide or lead are rather infrequent. Furthermore, positive or neutral overtone is also characteristic of many typical verbs (e.g., coax, flatter, talk). In fact, many typical verbs are judged negative precisely because of the verbs' frequent use in the into-causative. So if guide and lead appear to be neutral uses, this does not necessarily mean that they are qualitatively different from talk or flatter, which are clearly neutral or positive in isolation. Since there are no objective criteria to separate flatter, coax, and talk from guide, lead, and motivate by negativity, we largely refrain from referring to the subjective concept of polarity.

Second, even if certain aspects are absent in some usage events-which is a matter of degree, if not definition-, this does not invalidate the generalization over the vast amount of data that do exhibit these aspects. Rather, the question is whether negativity, manipulation, or causee reluctance are necessary conditions for constructional status in the first place. They are, in fact, near-inevitable corollaries of causation when $\mathrm{X}$ acts upon a human Y. It is for this reason that the intocausative has a statistical preference for verbs with direct cause-effect relationships with negative motivation on the part of the causer (scare, deceive, pressure) over more unspecific verbs in this respect (guide, lead, motivate).

This would not preclude an analysis of 'neutral' uses in a context of constructional polysemy (for MANIPULATION, TRIGGER, or PROMPT frames, cf. Gries and Stefanowitsch 2004; Stefanowitsch 2001, 2014). Crucially, constructional status does not depend on single verbs or infrequent usage events. The lexis-syntax interaction is, after all, the central argument of $\mathrm{CxG}$ (Goldberg 1995: Ch. 2). If that 
means that children end up reading more through gentle guidance rather than brute force (cf. 2), guide instantiates the construction ' $\mathrm{X}$ CAUSES Y TO DO Z by means of $\mathrm{V}$ ' rather straightforwardly-as do lead, motivate, or encourage.

This excursion was relevant for the diachrony of the into-causative, because unspecific, neutral, and positive verbs have been claimed to be on the increase. If true, this development could be indicative of semantic expansion and/or increased 'indirect causation' (Davies and Kim 2019; Rudanko 2006, 2011). However, since polarity and (in)direct causation depend on arbitrary definitions of how specific we take them to be, we focus on shifts in verb classes to approach change (cf. Section 4).

\subsection{Diachrony}

Since the earliest records in the late 17th century in (3), there has been no morphosyntactic change. The into-causative plausibly emerged from a series of constructional changes in the caused-motion construction, cf. (4), which was subject to shifts toward higher proportions of animate causees and more abstract goal arguments in the 16th and 17th centuries (Flach 2020). The simultaneous rise of -ing complements led to ambiguity between nominal (mourning) and verbal (truth-speaking) readings. As the verbal-reading strongly invited object-control interpretations, it was a relatively short step for speakers to extend the construction to sentential complements that define the into-causative today (3a, b):

(3) a. he was honestly trepanned ... into giving sentence against himself.

b. Besides, you Hector'd me into saying I lov'd both

[EEBO, 1678]

[EEBO, 1689]

(4) a. He moved the army into France.

b. It turned mirth into mourning.

[into NP]

c. They awed us into truth-speaking.

[into -ing ${ }_{\mathrm{N}}$ ]

[into - ing $\left.{ }_{\mathrm{N} \mid \mathrm{V}}\right]$

Due to a combination of low construction frequency and small corpora, the textual evidence is scarce in the 18th century. The few dozen clear examples in the century after the first attestations are parallel to contemporary use, with verbs of force (a), trickery (b), fear (c), or communication ${ }^{2}$ (d), and miscellaneous verbs (e):

2 An anonymous reviewer asks whether flatter should better be classified as a deception or trickery verb. The point is valid and illustrates the fuzzy boundaries. However, flatter evokes trickery here only because it appears in the into-causative; in isolation, it simply means 'excessive praise using speech' (cf. Section 2.1). Hence, flatter and similar speech-related verbs are classified as communication verbs. In addition, communication verbs are too rare in the 18 th century to cite a clearer example from this class (e.g., talk is not attested until 1834). 
(5) a. Yes, you villain, you have defiled my own bed, you have; and then you have charged me with bullocking you into owning the truth. [CLMET, 1749]

b. The house was large and elegant, and betrayed me into furnishing it rather better than suited my present circumstances [CLMET, 1763]

c. I wish I could teaze her into loving me a little. [CLMET, 1781]

d. the civilities which were shewn her, flattered her into believing she had excited a partiality that a very little time would ripen into affection

[CLMET, 1782]

e. Some days after I revived the subject of the drama, and led him into speaking of his own plays.

[COHA, 1824]

Communication verbs are conspicuously absent in clear object-control readings until the end of the 18th century (cf. Rudanko 2000: 72-73). As we will discuss in Section 4.1 in more detail, they gain significant ground only in the 20th century (see also Davies and Kim 2019: 40). Given their modern prevalence, this may seem surprising, but is in line with expectation, as we shall see below.

So what has changed, then? The previous studies that suggest semantic expansion and increased neutral uses (Davies and Kim 2019; Rudanko 2006) are based on the investigations of lexical innovation on a verb-type basis. By contrast, we will take a 'bird's-eye' perspective on verb classes and focus on collective changes that account for the quantitative and qualitative changes in a constructionist framework.

\subsection{Assumptions and hypotheses}

This section brings together the synchronic $\mathrm{CxG}$ analysis (Section 2.1) and the diachronic origin (Section 2.2). The assumed developmental path allows predictions about what to expect in the data. This can test the claim that the intocausative develops into a more reliable cue for causative meaning: as the vertical links between semantics and syntax grow stronger, the construction becomes more tolerant toward incompatible lexical material. In other words, as the construction takes over more functions in the division of labor between syntax and lexis, the compatibility constraints on verbs weaken. This makes syntactically and/or semantically incompatible verbs more likely to occur. Most generally, the construction changes from profiling movement into action to specifying manner of causation.

The pathway is illustrated in Figure 3. (A) represents the earliest stage, with a focus on movement into action, which reflects the origin in the caused-motion construction. (B) represents an into-causative that has inherited a result focus from 
the stage in (A). The focus on movement into action foregrounds the causee and backgrounds the cause(r), symbolized by the dashed line. (C) repeats the diagram for the contemporary into-causative (cf. Figure 1). The difference to (B) is indicated in bold font for manner and thicker lines for stronger links between semantics and syntax.

Two things should be borne in mind. First, the diagrams are abstractions rather than empirically motivated, and represent generalized landmarks of the developmental path. They are not tied to a particular period. While smaller steps could be posited on theoretical grounds, they can also neither be motivated empirically nor are they relevant for the discussion. Second, the assumed change

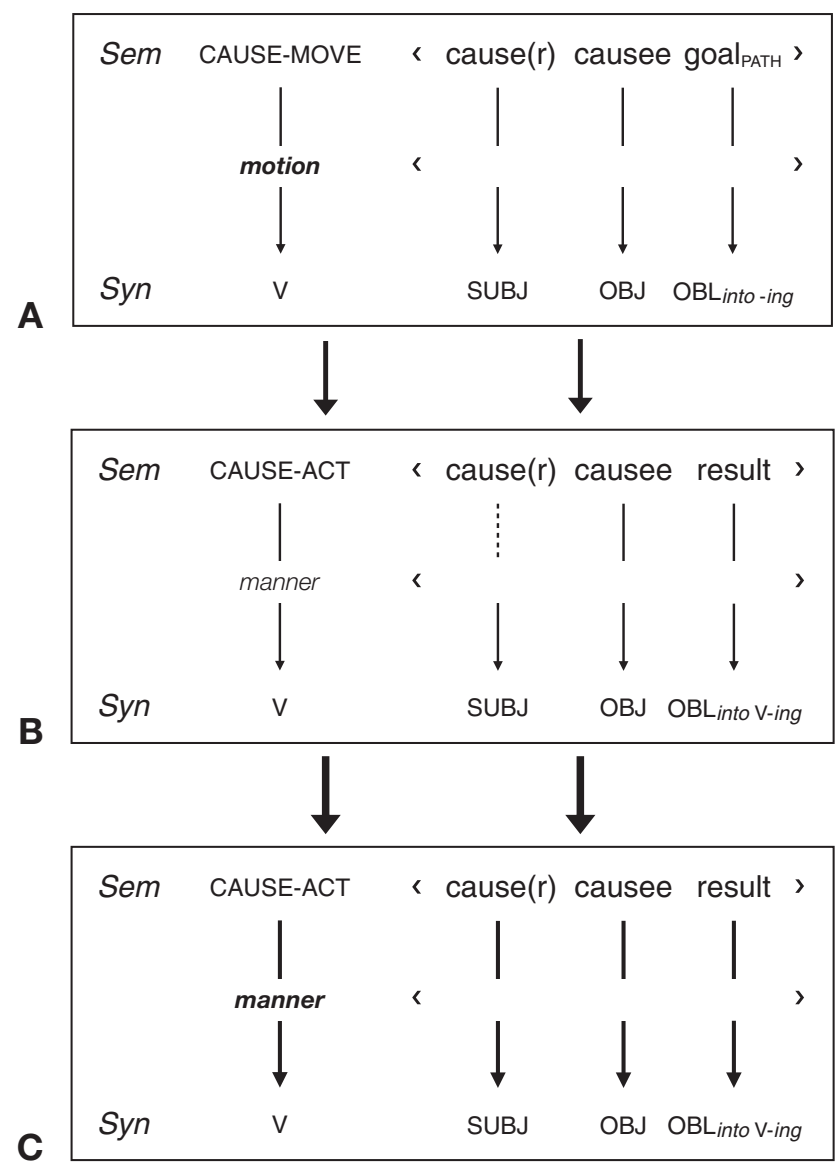

Figure 3: $\mathrm{CxG}$ representation of constructional change in the into-causative. 
from movement into action to manner of causation is relative and subtle, and shows only on aggregated data. Even the earliest examples in (3) specify the manner of causation, and, conversely, all modern examples retain a metaphorical movement into a state of action.

If the hypothesis of increasingly stronger argument mapping links is plausible, we expect shifts in the into-causative along the following three dimensions.

First, the construction should initially prefer compatible lexical material, i.e., verb classes that encode semantically transitive events, implying a direct cause-effect relationship between a causer and an animate causee. This is clearly the case for verbs of trickery (deceive, fool, mislead) and fear (intimidate, shock, terrify). Conversely, this is much less clearly the case for communication verbs (argue, chitchat, scream). Most communicative events are encoded in complex intransitives with prepositional obliques (talk to/with $s b$.) or with inanimate themes (argue a case). This argument also holds for force verbs: although they express relationships between causer and causee, many prefer inanimate objects (force a meeting, torture feelings) or alternative patterns (pressure/force somebody to do sth.).

Second, the into-causative should initially prefer verbs that usually occur in transitive uses with animate objects, i.e., those verbs with structures and semantics similar to the into-causative, while intransitive verbs should gain ground only over time. This prediction is related to the previous one, but focuses on the verbs' argument structure profiles in their uses outside the into-causative.

Third, we will look at the development of voice-marking. By backgrounding the causer, the passive focuses on the causee and hence foregrounds the effect on the causee. Recall that the implication of successful causation is contributed by the construction (Rudanko 2011: Ch. 2). This may be, relatively speaking, a more recent development. If we assume change from movement into action, which highlights the effect on the causee (he was forced into going; $\mathrm{cf}$. [B]), to manner of causation, which profiles both causer and causee (she forced him into going, cf. [C]), then actives should be relatively more likely in later periods. In other words, such a developmental pattern would indicate that the implication of accomplishment increasingly becomes part of constructional meaning.

From this perspective, rather than expanding functionally or becoming more neutral, the construction became more idiosyncratic in a CxG sense: tighter links facilitate a greater variety of verbs, particularly those that are semantically or syntactically less compatible. In the absence of changes in form and meaning, the shifts are subtle, and their empirical evidence is essentially indirect. We assume that constructional change shows as subtle distributional shifts (cf. Hilpert 2013: 16), not as a major restructuring of the constructional space. 


\section{Data}

The analyses are based on a CQP conversion of the mid-2015 offline version of the Corpus of Historical American English (COHA, 385m words; Davies 2010). Additional examples were extracted from Early English Books Online (EEBO; via CQPweb at Lancaster University), the Corpus of Late Modern English Texts (CLMET-3.1; De Smet et al. 2015), and the Corpus of Contemporary American English (COCA; Davies 2008). This section focuses on the extraction of the data for the intocausative; Section 4.2 below will describe two samples of verb uses outside the construction. $^{3}$

To minimize the influence of tagging errors with rare matrix verbs, ad-hoc conversions, or ambiguous -ing, which are rampant in the into-causative, the search pattern was maximally inclusive within heuristic sentence boundaries. The query matched any verb, followed by an unspecified number of tokens for objects of any length, followed by the string into, optional adverbs, and a string ending in -ing (resulting in 14,653 hits). ${ }^{4}$

All data points that were not into-causatives by the definition in Section 2.1 were manually removed, especially those with subject control (she put energy into solving the problem). Systematically nominal result predicates were also excluded: for instance, hiding only occurs in a nominal context (force sb. into hiding), while nursing, training, or managing also occur as heads of verbal complements (getting $s b$. into training for acts of folly). In addition, being-predicates were retained only if be was a copula (coax her into being nice to him), while the 'existence' sense was excluded (mostly call/bring sb./sth. into being).

The remaining 4,693 data points were annotated for the CLASS of the matrix verb (communication, fear, force, trickery, misc), voIcE (active, passive, reflexive), and PERIOD (cf. below). The CLASS variable is based on previous studies, but some classes were combined, e.g., fear/irritation or deception/trickery (Gries and Stefanowitsch 2004; Hunston and Francis 2000; Rudanko 2011; Wulff et al. 2007). A full list of all verbs by class is provided in the Appendix.

Table 1 summarizes the data. Compared to a previous study based on the same corpus, the number of types $(N=389)$ is lower, while the number of tokens $(N=4,693)$ is higher: Davies and Kim (2019: 34-36) report 544 types and 3,874 tokens. The lower number of types in the current set results from a narrower definition of the into-causative as an object-control pattern, excluding verbs such

3 All data is available at https://osf.io/2j63v/.

4 CQP query: [class="VERB"] []* "into"\%c [class="ADV"]* " .+ing?"\%c within s. This query also matched cases where the matrix verb is not tagged as a verb, but follows an earlier verb in the sentence and/or where the -ing string is tagged as an adjective or a noun. 
as bring, call, or throw. The type divergence may also be due to the restriction of the COHA offline version, where 10 words every 200 tokens are blanked, which potentially penalizes the (hapax) type count. The higher recall for tokens despite the limits of the offline version results from a more inclusive query that imposes fewer restrictions on the matrix verb, the length of the object, and the tag on the -ing-slot.

The variable PERIOD represents larger temporal bins, which were determined by Variability-based Neighbor Clustering (VNC; Gries and Hilpert 2012). VNC clusters adjacent decades in a bottom-up fashion, based on their similarity in relative frequency, in order to avoid arbitrary periodization. In the current analysis, larger bins are preferable because the into-causative is very infrequent in earlier COHA decades; larger bins hence safe-guard against a disproportionate influence of fluctuation in the data and facilitate the detection of developmental patterns by sensible data aggregation.

One such development is illustrated in the left panel of Figure 4. The line suggests a uniform increase in frequency (per million verbs [pmv]). However, the lengths of the VNC bins indicate a slight s-curve development: P3 (1910s-1940s) is the shortest period with four decades, while P1 and P2 (1810s-1850s, 1860s-1900s) comprise five and P4 (1950s-2000s) comprises six decades. Hence, P3 hints at a slight acceleration of usage, before the increase levels off in the second half of the 20th century. The horizontal bars represent period means of per million verbs (pmv).

Before we proceed with the analyses, we briefly discuss the increase in lexical diversity (right panel, Figure 4) and the problems associated with measuring productivity in a diachronic context. Proportions of types, tokens, and hapaxes depend on corpus size and construction frequency. As both increase (cf. Davies 2012), the ratios are based on a size-balanced sampler of COHA (16m tokens per decade from the 1840s). They were determined by averaging over 100 samples of 100 random verb tokens in each period, both for the construction and general main verbs in the corpus (cf. Perek 2018: 73 for a similar approach).

Table 1: Overview of into-causative token and types by period (COHA).

\begin{tabular}{lrrr}
\hline PERIOD & N/million verbs & Tokens & Unique types \\
\hline P1: 1810s-1850s & 15.44 & 113 & 46 \\
P2: 1860s-1900s & 69.24 & 763 & 136 \\
P3: $1910 \mathrm{~s}-1940 \mathrm{~s}$ & 109.33 & 1,214 & 200 \\
P4: $1950 \mathrm{~s}-2000 \mathrm{~s}$ & 140.94 & 2,603 & 283 \\
COHA & & $\mathbf{4 , 6 9 3}$ & $\mathbf{3 8 9}$ \\
\hline
\end{tabular}



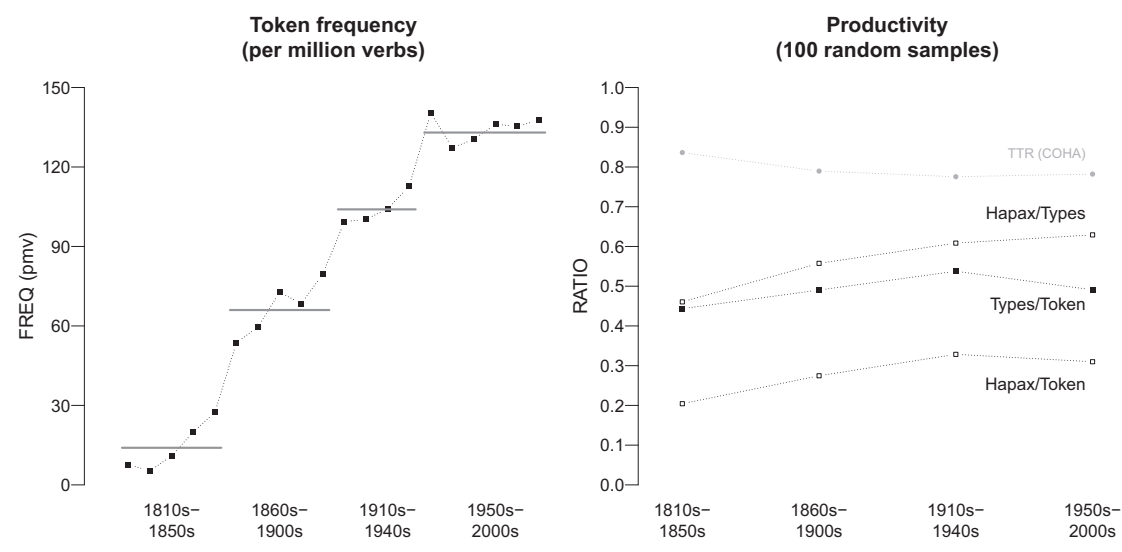

Figure 4: Frequency and lexical diversity in the into-causative (COHA). Left: frequency with VNC periods. Right: productivity, expressed in averaged values over 100 samples of 100 random intocausative tokens in each period; TTR $(\mathrm{COHA})$ shows average corpus type-token ratio by the same method (all based on a sampler version of COHA of $16 \mathrm{~m}$ tokens per decade).

The pattern appears to support the claim that the construction became more lexically diverse. The divergent shape of the curve for the type-token-ratio in $\mathrm{COHA}$ (TTR) suggests that this may not be an artefact of corpus composition. However, it remains doubtful whether this is an appropriate strategy, even if corpus and construction sizes are held constant in sampling. After all, the samples are drawn from a corpus that is fed from increasingly more varied sources: as more authors contribute to the corpus, more diverse topics are included. This also increases the likelihood of finding a greater diversity of verbs in samples. Therefore, diversity measured this way cannot easily be attributed to constructional change, which adds to the known mathematical problems of differently-sized corpora (for discussions on productivity-related issues in a diachronic context, see e.g., Barðdal 2008; Hilpert 2018a; Perek 2018). Hence, the analysis below focuses on verb classes rather than on verb types.

\section{Analysis}

Building on the discussion in Section 2.3, this section investigates changes in mapping links from three angles: shifts in the verb classes in the into-causative (Section 4.1), shifts in the argument structure profiles of verbs outside the intocausative (Section 4.2), and shifts in voice-marking (Section 4.3). 


\subsection{Shifts in verb classes}

\subsubsection{Aim and data}

This section analyses the distributional shifts in CLASS of 4,693 tokens. This is preferable over tracking frequencies changes of individual verbs, which may themselves become more or less frequent over time. We look at the interaction of CLASS and PERIOD, first by tokens, then by unique types.

\subsubsection{Results}

Table 2 shows the distribution of CLASS by PERIOD. Contingency tables are often assessed using a chi-square test, which confirms that the distribution shows a statistically significant interaction $\left(\chi^{2}=138.74, d f=12, p<0.0001\right.$, Cramér's $V=0.1)$.

However, since the $\chi^{2}$ value is a measure for the entire table, it masks detailed patterns, especially the direction of an effect. Row- or column-wise percentages would be more informative, but are hard to read and can only be expressed either by row or by column. As an alternative, residual-based association plots are an intuitive way to interpret tabular data (Friendly 1992; Zeileis et al. 2007). Association plots are essentially visualized chi-square tests that show each cell's contribution to the overall $\chi^{2}$ value. In contrast to line and bar plots of (relative) frequencies or (proportion) tables, they show several pieces of information at a single glance.

Table 2: Into-causative by CLASS and PERIOD (tokens).

\begin{tabular}{|c|c|c|c|c|c|}
\hline \multirow[b]{3}{*}{ CLASS } & \multicolumn{4}{|c|}{ PERIOD } & \multirow[b]{3}{*}{ SUM } \\
\hline & P1 & $\mathbf{P 2}$ & P3 & P4 & \\
\hline & $1810 s-1850 s$ & $1860 s-1900 s$ & 1910s-1940s & $1950 \mathrm{~s}-2000 \mathrm{~s}$ & \\
\hline trickery & 54 & 274 & 388 & 719 & 1,435 \\
\hline fear & 27 & 211 & 306 & 534 & 1,078 \\
\hline misc & 7 & 68 & 91 & 134 & 300 \\
\hline force & 8 & 107 & 225 & 588 & 928 \\
\hline communication & 17 & 103 & 204 & 628 & 952 \\
\hline SUM & 113 & 763 & 1,214 & 2,603 & 4,693 \\
\hline
\end{tabular}


Figure 5 is the plot for Table 2. Tile width mirrors frequency: more frequent classes have wider tiles and periods with more data points have wider columns. Most interesting for the detection of trends is the distribution of tile color, which indicates whether a CLASS-by-PERIOD combination is overrepresented (blue) or underrepresented (red) relative to the overall distribution. Color depth shows association strength: it is darker for stronger (dis)preference. If there were no interaction between verb classes and time, most or all cells would be grey. While the primary asset of association plots is the identification of patterns, it helps to know that residuals greater than \pm 2 indicate statistically significant cells at $p<0.05$ ( \pm 3 at $p<0.01$, etc.). Finally, note that although the effect size for this table is very weak in statistical terms (Cramér's $V=0.1$ ), this is expected for subtle changes that do not reshuffle a distribution.

Association plots are a simple, but very useful approach to patterns in diachronic or otherwise meaningfully ordered data (for a similar application to diachronic data, see Smirnova et al. 2019). They can indicate a trend horizontally from left to right and, depending on the order of rows, diagonally from top left to bottom right. For the into-causative, trickery, fear, and miscellaneous verbs are predominantly associated with earlier periods (cluster of blue tiles in the top left), while force and communication verbs are underrepresented (cluster of red tiles in the bottom left). This pattern is reversed in the later periods, especially when comparing P1/P2 to P4.

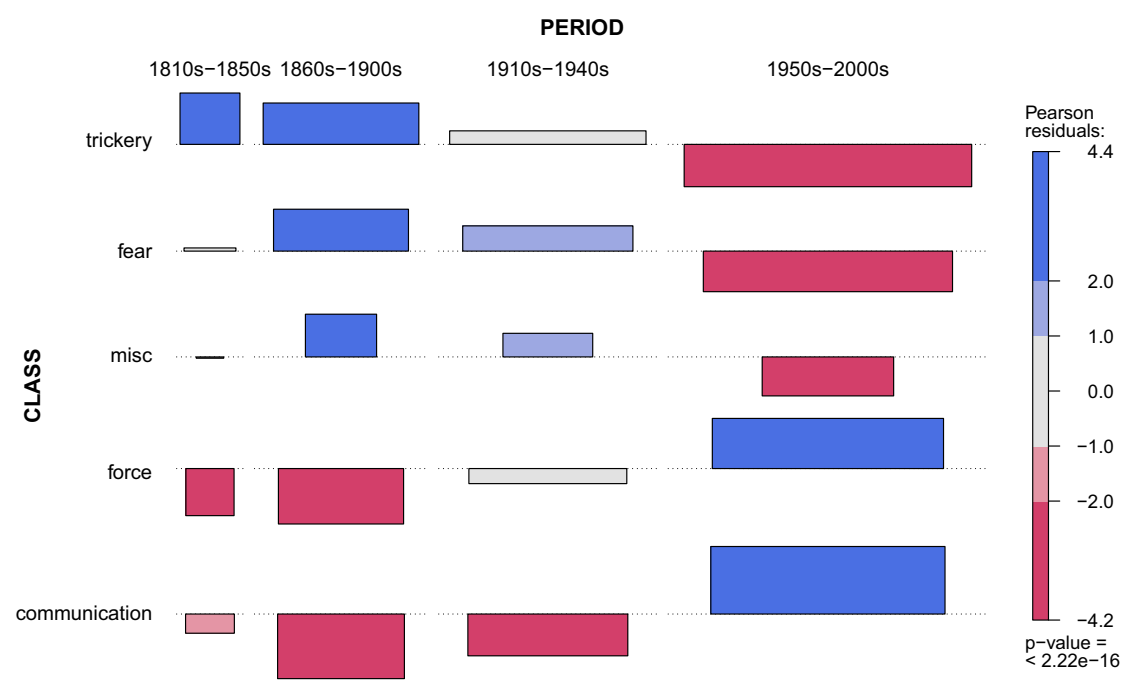

Figure 5: Residual-based association plot of CLASS by PERIOD (tokens). 
Two points should be noted with respect to the logic of association plots and how they should (not) be interpreted. First, distributions will necessarily show a cross-over somewhere in the table as the direction of association changes. The grey or lightly shaded tiles in P3 illustrate this effect. These cells must be assessed relative to whether they continue a trend. Crucially, the cross-over in P3 should not be interpreted in a way that attributes the major linguistic change to the 1910s-1940s. This is because the data for this (or any) period is not independent of the data in other periods (cf. Section 5). Second, the pattern does also not mean that trickery, fear, or miscellaneous verbs are on the decline. Quite to the contrary: they increase with an increasing construction, reflected in wider tiles in later periods. ${ }^{5}$ Thus, association plots focus on the likelihood of one class over another in a period relative to their occurrence across time. This means that individual cells are only meaningfully interpreted relative to all other cells. Put differently, association plots prioritize a trend ('interaction between variables') over individual variables (i.e., cells or tiles).

With one very notable exception, the same pattern emerges for types. Table 3 summarizes the distribution of unique types by period, visualized in Figure 6. While the table dimensions remain constant $(5 \times 4)$, there are fewer data points $(N=665)$, which explains lighter shades $\left(\chi^{2}=30.13, d f=12, p<0.01\right.$, Cramér's $V=0.12)$.

The overall trend holds, except for communication verbs, which have no typeassociation with a period in this set (row of grey tiles). This is in part because they are the class with the fewest types $(\sim 10 \%)$, despite their large share in tokens $(>20 \%)$.

Table 3: Into-causative by CLASS and PERIOD (unique types).

\begin{tabular}{lrrrrr}
\hline & \multicolumn{5}{c}{ PERIOD } \\
\cline { 2 - 6 } CLASS & P1 & P2 & P3 & P4 & \\
\hline trickery & 1810s-1850s & 1860s-1900s & 1910s-1940s & 1950s-2000s & SUM \\
fear & 17 & 28 & 37 & 46 & 128 \\
misc & 16 & 50 & 65 & 68 & 199 \\
force & 3 & 19 & 31 & 66 & 119 \\
communication & 5 & 26 & 48 & 73 & 152 \\
\hline SUM & 5 & 13 & 19 & 30 & 67 \\
\hline
\end{tabular}

5 This also holds for the data from the COHA sampler and/or relative (pmv) frequency. 


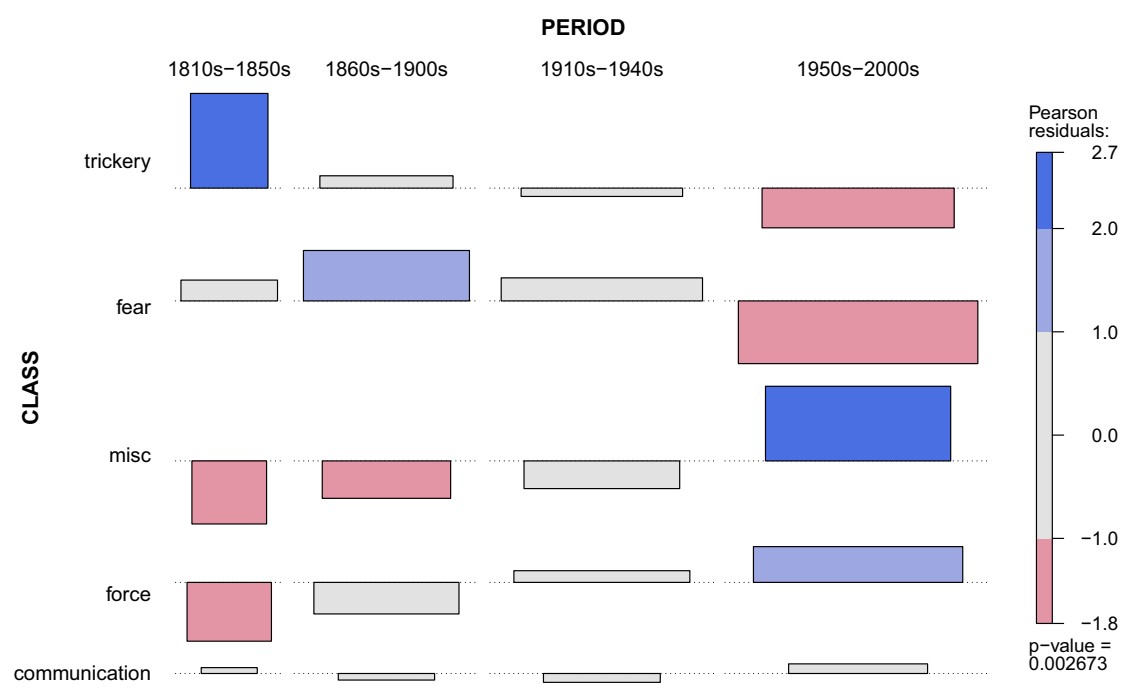

Figure 6: Into-causative by CLASS and PERIOD (unique types).

The only marked and relevant difference over the token-based perspective is the pattern of the miscellaneous verbs. In technical terms, this is very much for the inverse reason as for the communication verbs: miscellaneous verbs make up roughly $18 \%$ of types (119/665; cf. Table 3 ), but contribute only $6 \%$ of tokens (300/4,693; cf. Table 2). The majority of the miscellaneous verbs are hapaxes or lowfrequency verbs, with the exception of drive and lead. However, in linguistic terms, their early overrepresentation by tokens (like trickery and fear verbs) and their later overrepresentation by types (like force and communication verbs) is not a fluke in the data, but indicative of a construction-internal change, as we discuss below.

\subsubsection{Discussion}

Recall that typical two-argument verbs with direct causer-causee relationships were expected to be initially overrepresented, because these are most compatible with the constructional semantics of the into-causative. Conversely, classes with a less clear collective behavior in semantic transitivity should initially be underrepresented. This is exactly what we find: the former is borne out by the positive association of trickery and fear verbs with earlier periods, while the latter holds for force and, at least by tokens, for communication verbs, which are relatively more likely in later periods. 
The pattern for force verbs appears unexpected. Intuitively, force, coerce, or pressure are typical verbs for expressing cause-effect relationships between causer and causee. We should thus expect them to pattern like trickery of fear verbs. However, a closer look at their historical behavior speaks against this expectation and in favor of a construction-internal change in line with the hypothesis.

On the one hand, there is the question of changing frequencies: some verbs enter the language and become more frequent, others become less frequent. In theory, this can affect the relative rise of this class in a construction, if the majority of force verbs are new (discourse or textual) developments. An example for a new verb is pressure, which is first attested in the construction in the 1940 s and is one of the most frequent force verbs in the construction today. It is also a relative newcomer to English, which appears from the 1880s onwards, but reaches its modern-day frequency only by the 1960s. Other examples include cudgel, which has become less frequent, both in the construction and the corpus, and torture, which decreases in the corpus, but has remained constant in the construction. Such examples eliminate the (hypothetical) possibility that the force verbs in the into-causative are new verbs in the language.

On the other hand, however, the possibility of pre-empting constructional preferences is more interesting: synchronically, force verbs prefer alternative patterns, most notably to-infinitival complements (Rudanko 2006). However, in 19th century texts, force was neither predominantly used transitively with an animate object (we force the people), nor with a to-complement (we force them to comply). An analysis of 25 random force observations per decade shows that only $48 \%$ occur with an animate object in $\mathrm{P} 1$ (which rises to $80 \%$ in $\mathrm{P} 4$ ) and only $36 \%$ with a to-complement (which rises to 63\% in P4). More typical uses in the 19th century were force the door open or force a discussion. By the same token, it was feelings and minds rather than people that were tortured, at least in 19th century writing. While these competing argument structures did not preclude uses of force or torture in the into-causative, they affected their probability to occur, because they were semantically less compatible. In other words, there are preempting constructions, but in a slightly different form. We will discuss shifts in argument structure profiles of matrix verbs more systematically in the next section.

Finally, the diverging behavior of miscellaneous verbs by tokens and types deserves some discussion (cf. Section 4.1.2). Recall from Section 2 that claims about expansion toward neutral or positive uses hinges mostly on the development of verbs in this class (Davies and Kim 2019; Rudanko 2006). As Figure 5 shows, they are overrepresented in P1 and P2 by tokens. Also recall that the tokens in this class are contributed primarily by lead and drive, which are the only systematically 
licensed motion verbs. ${ }^{6}$ Given the skew, the association of this class with earlier periods by tokens is a remnant of the origin in the caused-motion construction. By contrast, miscellaneous verbs are overrepresented in later periods by types (Figure 6).

These patterns reflect two overlapping developments, which can both be linked to construction-internal changes. On the one hand, the shift away from profiling movement into a location means that the high-token contributors lead and drive have a decreasing likelihood to occur. Hence these verbs are increasingly underrepresented by tokens. On the other hand, the shift toward profiling the manner of causation means that the construction becomes more capable of licensing atypical intransitive verbs. Hence, miscellaneous verbs are progressively overrepresented by types. New types in P4 are mostly hapaxes with intransitive or transitive-inanimate semantics (e.g., brainstorm, catapult, direct, groom, initiate, rationalize, subsidize, or trigger). In other words, these verbs feed on stronger mapping links over time.

This observation resolves two apparently conflicting earlier findings. Rudanko (2006) suggests that the construction has become more neutral, based on an increase in manner-neutral verb types. Davies and Kim (2019: 44) and Kim and Davies (2016: 80) reject this claim as they do not find a substantial increase in manner-neutral tokens. ${ }^{7}$ The association perspective above reconciles these positions: both approaches tap into the same phenomenon, they just look at two sides of the coin.

\subsection{Shifts in verb argument structure}

\subsubsection{Aim and data}

The discussion of force in the previous sub-section raises the question if shifts in argument structure preferences provide systematic evidence of constructional change. Weaker mapping links should show in an initial preference for verbs which are readily compatible with constructional syntax and semantics (i.e., transitive verbs with animate objects). As mapping links become stronger, the

6 Proportion of lead/drive tokens in the miscellaneous class (P1-P4): 85\%, 67\%, 51\%, and 26\%. 7 The token frequency plot in Davies and Kim (2019: 44) does show an increase for manner-neutral verbs. However, since the construction increases, their interpretation is probably appropriately cautious. In any case, it illustrates the advantage of association plots over frequency graphs: while Davies and Kim (2019: 44) argue that manner-neutral verbs have always been present (rejecting Rudanko's claim of a recent development), the association view disentangles the effects of tokenand type-based changes. 
construction should increasingly license verbs that are less compatible (i.e., transitive verbs with inanimate objects and intransitive verbs).

Since it is not feasible to survey argument structure profiles for all 398 types in sufficient quantities for each verb in each decade, two samples were devised, one type-balanced and one unbalanced. If the results from both samples converge, they provide evidence that the results are not due to a particular sampling strategy.

For the type-balanced sample, all matrix verbs that occur in the into-causative in a given period were queried in COHA in that period. Then, 100 observations of each verb were randomly selected; if a verb occurs fewer than 100 times, all observations were included. From this list, 200 observations per decade were randomly selected (excluding into-causatives). Finally, from the list of 4,000 tokens for all 20 decades, 500 observations were sampled per period, for a total of 2,000 data points. This sampling method avoids a token overrepresentation of atypical verbs which are frequent in the corpus (guide, work) and avoids a token underrepresentation of typical verbs which are rare in the corpus (betray, seduce, deceive). However, get was excluded, where the mismatch between corpus and construction frequencies is greatest.

The second sample is unbalanced. Like the balanced sample, each matrix verb that occurs in a period was queried in that period. Then, 200 observations per period were randomly selected (excluding into-causatives), irrespective of how frequent the verb types are, for a total of 800 observations (get was again excluded).

All observations were coded for the ANIMACY of the direct object (animate, inanimate) or as intransitive if an NP object was absent. Animate objects include humans, animals, and collectives (government, congress). Complex intransitives with prepositional obliques (talk to/of sb./sth., scream at sb.) or sentential complements (she argues that $\mathrm{S}$, he threatens to $\mathrm{V}$ ) were coded as intransitive. Coding for argument structure in this way is a simple but effective approximation and suitable to capture verb subcategorization preferences for the purpose of the present analysis.

\subsubsection{Results}

The overall patterns are identical for the type-balanced (Table 4, Figure 7) and the unbalanced samples (Table 5, Figure 8). This suggests a construction-internal effect: earlier periods are associated with verbs that are used transitively with animate objects, while verbs with inanimate objects in intransitive patterns are dispreferred. This pattern is reversed in later periods, which are associated more strongly with inanimate objects and intransitives. 
Table 4: Object animacy of verb uses outside the into-causative (type-balanced sample).

\begin{tabular}{lrrrrr}
\hline & \multicolumn{4}{c}{ PERIOD } & \\
\cline { 2 - 6 } & P1 & P2 & P3 & P4 & \\
PATIENT/THEME & $\mathbf{1 8 1 0 s - 1 8 5 0 s}$ & $\mathbf{1 8 6 0 s - 1 9 0 0 s}$ & $\mathbf{1 9 1 0 s}-1940 s$ & $\mathbf{1 9 5 0 s}-2000$ s & SUM \\
\hline animate & 383 & 301 & 281 & 251 & 1,216 \\
inanimate & 80 & 100 & 105 & 152 & 437 \\
intransitive & 37 & 99 & 114 & 97 & 347 \\
\hline SUM & 500 & 500 & 500 & 500 & 2,000 \\
\hline$x^{2}=97.08, d f=6, p<0.0001$ & Cramér's $V=0.16$ & & & &
\end{tabular}

$X^{2}=97.08, d f=6, p<0.0001$, Cramér's $V=0.16$.

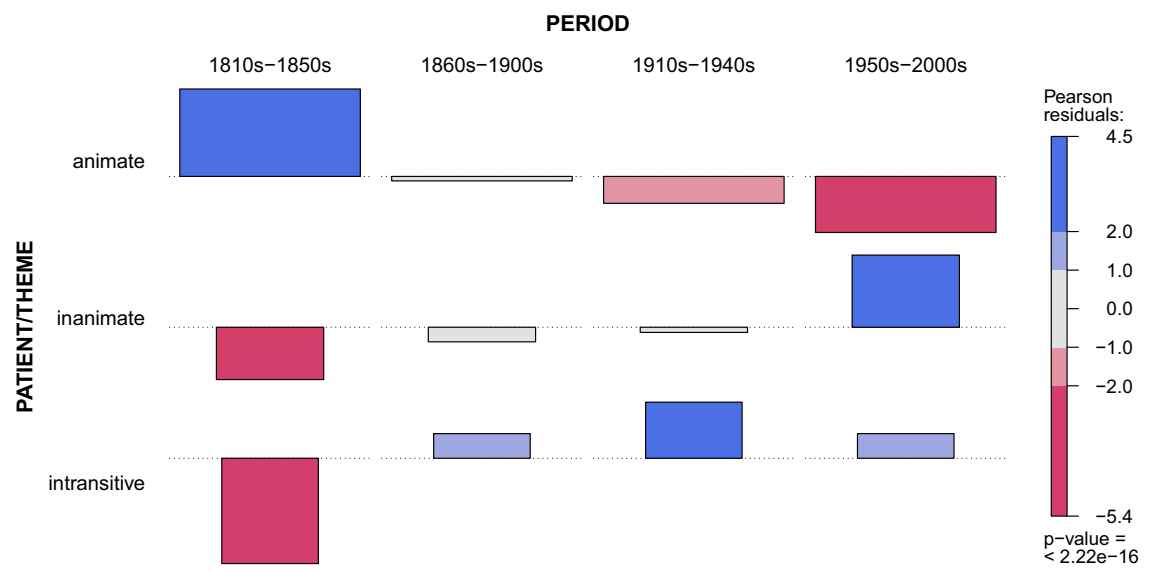

Figure 7: Object animacy in verb uses outside the into-causative (type-balanced sample).

\subsubsection{Discussion}

Although the patterns are based on data beyond the into-causative, they are insightful in the following way. In the earliest periods, the typical verb that occurs in the into-causative is used transitively with an animate object outside this construction. By contrast, verbs with inanimate objects and intransitive verbs are relatively more likely only in later periods. Again, this does not mean that transitive verbs decrease; but they occur with a lower probability relative to other verbs. In other words, incompatible lexical material 'gains ground' over time.

The patterns make sense assuming weaker initial mapping links. Transitive verbs with a statistical preference for animate objects are more compatible with causative events that involve an animate causee; they do not 'require' arguments supplied by the construction as much as intransitive verbs. Over time, stronger 
Table 5: Object animacy of verb uses outside the into-causative (unbalanced sample).

\begin{tabular}{lrrrrr}
\hline & \multicolumn{4}{c}{ PERIOD } & \\
\cline { 2 - 6 } & P1 & P2 & P3 & P4 & \\
PATIENT/THEME & 1810s-1850s & 1860s-1900s & 1910s-1940s & 1950s-2000s & SUM \\
\hline animate & 105 & 68 & 50 & 44 & 267 \\
inanimate & 31 & 49 & 53 & 58 & 191 \\
intransitive & 64 & 83 & 97 & 98 & 342 \\
\hline SUM & 200 & 200 & 200 & 200 & 800 \\
\hline$X^{2}=51.44, d f=6, p<0.0001$, Cramér's $V=0.18$. & & & &
\end{tabular}

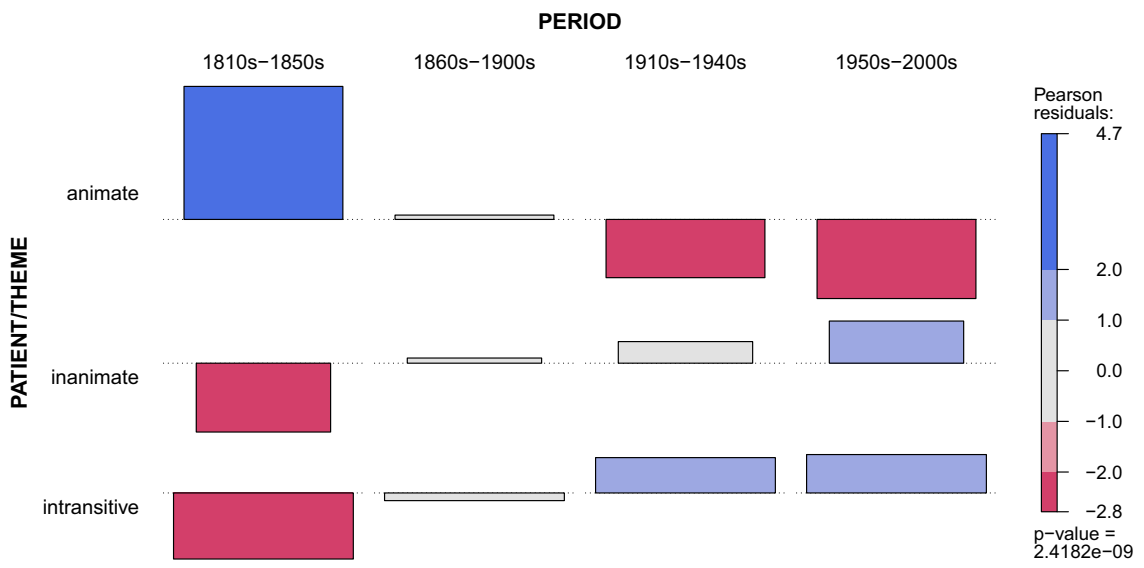

Figure 8: Object animacy in verb uses outside the into-causative (unbalanced sample).

links increase the probability that the construction occurs with atypical (transitive-inanimate) or incompatible (intransitive) verbs. The fact that intransitives are associated with the construction earlier than transitives with inanimate objects (indicated by earlier blue tiles for intransitives) may have to do with the fact that intransitives include complex intransitives with obliques. This distinction was not separately coded, because the difference between oblique and adjunct is often unclear. But complex intransitives with an animate referent in the oblique (talk to $s b$., scream at $s b$.) are arguably more compatible with the construction than transitives with inanimate objects (argue a point, ridicule authority).

The patterns converge with Rudanko's (2005) detailed by-verb analyses, which found that many of the new manner-neutral verbs in the 20th century prefer verbal to-complements. Over time the into-causative increasingly licensed verbs independently of verb semantics or pre-empting argument structure profiles. The 
approach lends support to the methodological focus on verb classes, as it is less sensitive to the subjectivity of coding for polarity.

Note at this juncture that the 'cross-over effect' for argument structure (P2, 1860s-1900s; Figures 7 and 8) occurs earlier than for semantic classes (P3, 1910s1940s; Figures 5 and 6). Although association plots show relative shifts, this could tentatively be interpreted such that the construction's tolerance first extended to syntactically less compatible verbs within semantically compatible classes, before it also extended to semantically incompatible classes.

\subsection{Shifts in voice-marking}

\subsubsection{Aim and data}

This section looks at shifts in voice-marking: into-causatives are either active (I deceive you into believing), passive (I was deceived into believing), or reflexive (I deceived myself into believing). Recall that the passive foregrounds a causee and hence profiles the resulting effect, while the active profiles all participants. Also recall that the into-causative implies that the causation was successful. Therefore, the distributional patterns should show a relative shift from passive to active marking: actives should be relatively more likely in later periods as the implication of accomplishment becomes part of constructional meaning. This section investigates voice-marking on all 4,693 into-causative tokens.

\subsubsection{Results}

Table 6 shows the distribution of VOICE by PERIOD, visualized in Figure 9. There is a significant interaction of voice-marking with time in line with the expectation: passives are overrepresented in the first two periods, while reflexives and actives characterize periods $\mathrm{P} 3$ and $\mathrm{P} 4$, respectively.

One caveat here is the general decrease of passives in COHA. However, the developments do not proceed in parallel. Kendall's $\tau$ (Hilpert and Gries 2009) ${ }^{8}$ shows that the passive declines more uniformly in the corpus $\left(r_{\tau(20)}=-0.89\right)$ than in the into-causative $\left(r_{\tau(20)}=-0.58\right)$, reflecting an initially faster rate of decline in

8 Kendall's $\tau$ ranges from -1 (perfect negative correlation) to 1 (perfect positive correlation). The coefficient can be interpreted as measuring the stability of decrease or increase, respectively, where values closer to 0 indicate a non-uniform development (or the absence of a trend). Kendall's $\tau$ is measured across 20 COHA decades for reasons of sample size. 
Table 6: VOICE by PERIOD in the into-causative.

\begin{tabular}{lrrrrrr}
\hline & \multicolumn{5}{c}{ PERIOD } & \\
\cline { 2 - 6 } VOICE & P1 & P2 & P3 & P4 & \\
\hline passive & 1810s-1850s & 1860s-1900s & 1910s-1940s & 1950s-2000s & SUM \\
reflexive & 56 & 332 & 363 & 582 & 1,333 \\
active & 2 & 18 & 77 & 115 & 212 \\
\hline SUM & 55 & 413 & 774 & 1,906 & 3,148 \\
\hline$X^{2}=173.77, d f=6, p<0.0001$, Cramér's $V=0.14$. & 763 & 1,214 & 2,603 & 4,693 \\
\hline
\end{tabular}

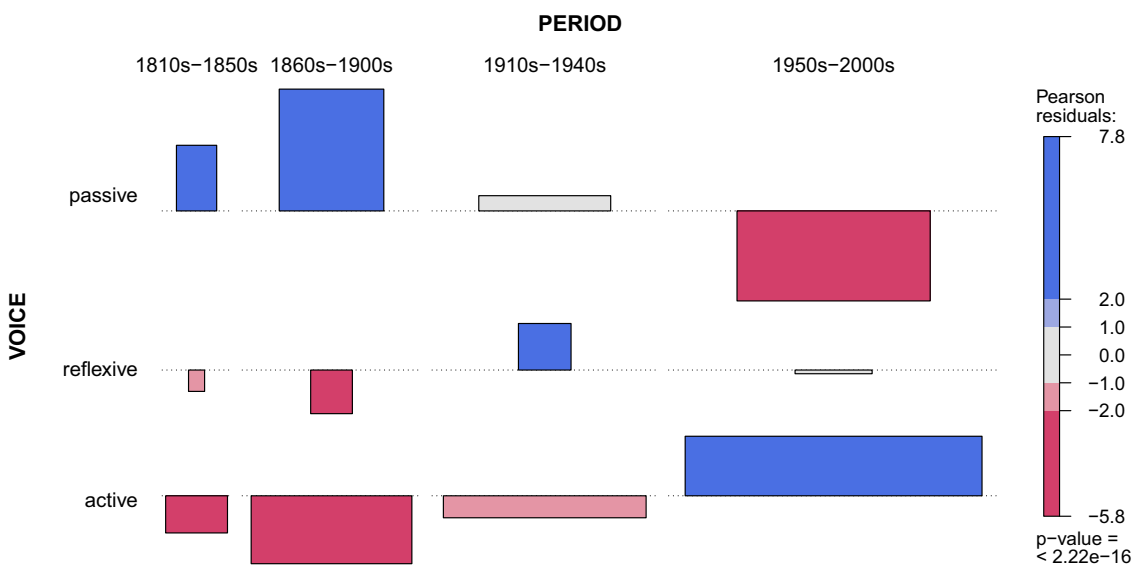

Figure 9: Residual-based association plot of VOICE by PERIOD.

the construction. That voice-marking on the into-causative is a corpusindependent development is further supported by the increase of reflexives in the construction $\left(r_{\tau(20)}=0.65\right)$, despite their decrease in the corpus $\left(r_{\tau(20)}=-0.81\right) .{ }^{9}$ Reflexives, which have co-referential causer and causee, are semantically similar to actives. Hence, their intermediate developmental position between passives and actives adds weight to the assumption that this represents a meaningful construction-internal development.

9 Approximating passives: $b e[a d v]^{*} v . n$. Approximating reflexives: a main verb (tags vv. $\left.{ }^{\star}\right)$ followed by a reflexive pronoun (tags ppx1, ppx2). 


\subsubsection{Discussion}

Similar to the analyses above, there is a systematic trend of stronger mapping links. Earlier periods have a higher probability of profiling causee and result in the passive. Again, the pattern does not imply that passives become less frequent over time: they increase with an increasing construction. What we observe is, again, a subtle relative shift within the construction.

A potential confound pertains to the interaction of voice, the passivizability of verbs, and their development in the construction. Since communication verbs are generally less likely in the passive (?'she was chitchatted), their stronger association with the construction in later periods could be the main contributor to the increase of actives. However, three points suggest that the rise of communication verbs alone cannot account for this pattern.

First, force verbs, which are most strongly attracted to the passive, also increase over time. This potentially cancels out the effect of more frequent communication verbs. Second, with the exception of (some) communication verbs, the verbs' general attraction to the passive does not influence voice-marking in the into-causative in a synchronic data set (cf. Flach 2018). Third, all verbs in the intocausative are passivizable (?'she was chitchatted, but she was chitchatted into V-ing). In other words, the passive in the into-causative profiles the relationship between cause and causee independently of a verb's passivizability outside the construction.

While the evidence for constructional change here is indirect, the interaction between voice and time is plausibly interpretable under the assumption that the implication of successful causation becomes part of constructional meaning that makes active uses more likely (cf. Section 2; Rudanko 2011: 13-16).

\section{General discussion}

This final section serves two purposes: first, it puts the results into the context of previous research. Second, as this paper tried to account for the changes from a Diachronic Construction Grammar (DCxG) perspective, the insights will be used to address one of the central open issues in the emerging field of DCxG. As diachronic linguists increasingly adopt constructionist ideas, the relationship between constructionalization, i.e., the creation of a new form-meaning pair, vs. constructional change, i.e., change(s) within a form-meaning pair (Traugott and Trousdale 2013), is currently undergoing conceptual and empirical refinement (e.g., Flach 2020, Hilpert 2013, 2018b; Sommerer and Smirnova 2020, and the contributions therein). 
As regards the first point, this paper argued that the changes in the intocausative involved, most abstractly, a shift from profiling motion into action to specifying manner of causation. Applying the classic synchronic CxG idea of argument mapping between syntax and semantics (Goldberg 1995), we investigated the hypothesis that the construction's ability to supply argument and participant roles grew over time. Stronger links between semantics (causer, causee, result) and syntax (subject, object, oblique) increased the likelihood that the construction tolerated semantically or syntactically incompatible verbs. Since stronger links correlate with greater constructional idiosyncracy, the form itself became a more reliable cue for the expression of causative meaning. This facilitated the usefulness of the construction in more discourse-functional contexts, which then contributed to its increase in usage.

Three case studies tested the predictions of these assumptions, and the results provide evidence for a constructionist scenario. First, the construction initially preferred verb classes with direct cause-effect relationships between causer and causee and dispreferred classes which show less consistent behavior in this regard. Second, independent of semantic class, the into-causative initially preferred transitive verbs with animate objects (i.e., syntactically compatible verbs), and dispreferred intransitive verbs or verbs with inanimate objects. Third, the intocausative initially had a higher likelihood of occurring in the passive-which profiles causee and result-over the active, which profiles both causer and causee. This indicates that the implication of successful causation may have become part of constructional semantics. As a tentative hypothesis, the results in Sections 4.1 and 4.2 indicate that constructional tolerance first spread to syntactically atypical verbs that are semantically similar, before it spread to verbs that are both syntactically and semantically atypical, although this may require more fine-grained analyses.

The association-based view is a methodological alternative to type- or tokenbased investigations of changes in (mostly) low-frequency verbs. This approach is more multifactorial than normalized frequency curves and therefore less sensitive to shifts in the English lexicon; it is also more objective than interpreting proportion plots (e.g., stacked bar plots). In addition, it safeguards against lexical variability in an unbalanced corpus that increases in size.

Previous studies suggested that the rise in frequency is due to functional expansion of the into-causative (Davies and Kim 2019; Rudanko 2006, 2011). These accounts are not necessarily incompatible with the present study, which makes no specific claims about expansion or the emergence of (potentially neutral) subsenses. However, the argument is that expansion, however defined, is a corollary of changes in argument mapping. As the construction becomes more idiosyncratic and tolerates a greater lexical variety, it licenses more verb types in more diverse 
contexts. This can create the impression of semantic and/or functional expansion, which may however be due to corpus composition or greater diversity in the publishing culture. ${ }^{10}$ In any case, it should be borne in mind that stronger links do not have to lead to increased usage (see Mair 2004 for this argument in grammaticalization).

Three processes were side-lined that are usually assumed to accompany grammatical change, i.e., changes in productivity, schematicity, and compositionality (Traugott and Trousdale 2013: 22). They do not apply to the into-causative in the way they are normally understood. First, productivity in the into-causative is productivity within classes-these classes do not (dis)appear. It is possible that an elevated lexical variability is to no small extent a function of English (or it is published textual record) becoming more lexically diverse. Recall that comparing productivity over time is inherently problematic, especially if both construction frequency and corpus size increase: if we fish in a larger pond that is fed by more diverse sources, we will necessarily catch more different types of fish, especially if using a larger fishing net (representing an increasing construction). Hence, comparing productivity may only make sense for within-period comparisons between subsenses that serve as minimal 'controls' to counterbalance shifts in textual material (see Perek 2018 for an example of investigating productivity in the subsenses of the way-construction). Second, the construction has always been fully schematic, owing to its emergence from the lexically underspecified causedmotion construction. Third, therefore, its compositionality was low from the outset. Whether the shift from movement into action to manner of causation constitutes lower compositionality is a matter of definition.

On a similar note, it is for these reasons that the into-causative does not lend itself straightforwardly to an analysis as a grammaticalizing construction (Hopper and Traugott 2003). Unlike many other constructions, its emergence resulted from a rather abrupt reanalysis, not a gradual development from erstwhile lexical contexts (cf. Section 2.2). Since the into-causative was grammatical from its first attestation-and its predecessors are instances of the caused-motion construction-its subsequent development could only fall under 'secondary grammaticalization'. Yet, it is difficult to envisage what 'becoming more grammatical', 'acquiring new grammatical functions', or 'being more grammaticalized' means for the into-

10 An anonymous reviewer asks whether this is a chicken-and-egg question: could lexical diversity drive 'usability' in more discourse-pragmatic contexts? It is true that the processes are mutually reinforcing and overlapping and thus empirically difficult to disentangle. However, increased lexical diversity on a large scale logically presupposes constructional tolerance to license the larger diversity in a greater range of new contexts in the first place. 
causative (for an overview and critical assessment of secondary grammaticalization, see Breban 2014).

How do the results now tie in with current questions in DCxG? With the popularity of constructionist approaches in synchronic linguistics also came an interest in applying these ideas to language change. As the diachronic constructionist perspective adds the change dimension, the notion of constructionalization (Traugott and Trousdale 2013), i.e., the creation of a new construction, gained considerable popularity. However, constructionalization has recently received critical evaluation (Börjars et al. 2015), particularly in contrast to constructional changes (Flach 2020; Hilpert 2018b). While I critically evaluate constructionalization with respect to the emergence of the into-causative until its first attestation elsewhere (Flach 2020), the remainder of this discussion assesses constructionalization with regard to its endpoint.

In brief, constructionalization is defined as the creation of a new formmeaning pairing that has both a new form and a new meaning $\left(F_{\mathrm{NEW}}-M_{\mathrm{NEW}}\right)$. It is hence to be distinguished from changes in either form or meaning, which are constructional changes that do not lead to a new construction (Traugott and Trousdale 2013: 22, 27). Since constructionalization is assumed to be gradual and accompanied by constructional changes, an inherent problem is that there is neither a cut-off between 'pre-constructionalization constructional changes' and constructionalization on the one hand, nor between constructionalization and 'post-constructionalization constructional changes' on the other. In other words, it is unclear which constructional changes that lead to $F_{\mathrm{NEW}}-M_{\mathrm{NEW}}$ are part of pre-, con-, or post-constructionalization. Under this definition, the distinction between constructionalization and constructional change is subject to the Sorites Paradox ('How many grains of sand are a heap?'; cf. Börjars et al. 2015; Flach 2020; Hilpert 2015, 2018b).

We can take the into-causative as an example to illustrate why the distinction between 'constructionalization' and 'constructional change' may not be helpful. Until the first attestation, all empirical records of [SUBJ V OBJ OBL] are fully accounted for as instances of the caused-motion construction and constructional changes therein (Flach 2020). It is therefore impossible to determine the beginning of the constructionalization of the into-causative. For example, even the rise of -ing gerunds was a contributing factor, which itself has a history that spans multiple centuries as far back as Old English (Fonteyn 2019). After the first attestation, the into-causative has not changed in $F$ until today. Where then can we place the end of constructionalization? That is, which of the changes since the late 17th century accompany its constructionalization (con-constructionalization changes) and which do not (post-constructionalization changes)? One possibility is to assume that constructionalization requires conventionalization, i.e., spread through the 
speech community, in order to count as change rather than innovation (Traugott and Trousdale 2013: 2). However, this may be the mother of sand heaps (cf. Börjars et al. 2015: 364): measuring conventionalization varies linguistically with the specificity of the construction and empirically with the size of a corpus. ${ }^{11}$

We should emphasize at this juncture that this is neither meant to deny the role of conventionalization in grammatical change, nor does it imply that conventionalization cannot be measured. There is a growing body of work that addresses these questions, in particular the relationship between the individual and the community and their role(s) in grammatical change (e.g., De Smet 2016; Fonteyn 2017; Petré and Van de Velde 2018). However, the argument is that conventionalization is best seen as a property of constructional change, alongside any type or combination of formal, semantic, social and/or discourse-pragmatic change(s) (Hilpert 2013: 16). To be sure, once we find textual evidence of a construction in corpora, it is a reasonable assumption that the construction was already conventional enough to be used in publishing or (private) correspondence, even if only in a very small (sub)section of the speech community. This view makes it easier to converge grammatical change with the idea of emergent grammar (Hopper 1987), as slight form and/or meaning changes occur in altered replication of conventional material (Croft 2000) through the speech community without necessarily leading to a new construction.

In other words, there appear to be two sides to the Sorites Paradox, one that presents itself as an empirical problem (measuring conventionalization) and one that presents itself as an ontological one (defining constructionalization). It is the latter we evaluate critically here. ${ }^{12}$

Returning to the conceptual problem of constructionalization, it depends on one's definition of meaning whether the into-causative has changed in $M$. If its meaning is ' $\mathrm{X}$ CAUSES Y TO DO Z (by means of V)', then the into-causative has been a stable form-meaning pair for over 300 years $\left(F_{0}-M_{0}\right)$. We are unable to determine the end of constructionalization this way. If we assume $M$ to be manner of causation, then its meaning is emergent, i.e., as a sequence of changes $F_{0}-M_{0}>F_{0}-$ $M_{1}>F_{0}-M_{2}>F_{0}-M_{3}$ etc. (Börjars et al. 2015; Hilpert 2018b). Do we assume that the steps $M_{0}, M_{1}, M_{2}$, or $M_{3}$ are part of the constructionalization of $F_{\mathrm{NEW}}-M_{\mathrm{NEW}}$ ? If yes, then constructionalization is potentially infinite. If no, this raises the question of

11 The more contextually specific or infrequent a construction and its predecessor are, especially at the initial stage, the more it depends on the corpus to cover its (potential) discourse-pragmatic environment in sufficient quantity. If it weren't for the 1-billion Early English Books Online collections, dating the construction's first attestation to the 17th century would not have been possible (cf. Flach 2020 for a detailed discussion).

12 I thank an anonymous reviewer for cautioning against creating the impression that conventionalization is unjustifiably sidelined here. 
the status of the intermediate steps, since every step $M_{\mathrm{N}}$ necessarily creates a new intermediate position between $M_{\mathrm{N}}$ and $M_{\mathrm{N}-1}$ and $M_{\mathrm{N}+1}$.

This also cannot locate the end of constructionalization as $F_{\mathrm{NEW}}-M_{\mathrm{NEW}}$. The methodological approach illustrates this. If we restrict the data to nine decades in the 20th century (1910s-1990s), which simulates a smaller available corpus, we get the same pattern of change, just over a shorter time span (Figure 10). Conversely, we should find the same distribution over a longer time span, if we had sufficient textual records for the construction in the 18th century. Put differently, the change from motion to manner is relative, not tied to a specific period. Hence, it is empirically impossible to determine $M_{0}, M_{1}$, or $M_{2}$, since the required steps could be infinitesimally small and their demarcation arbitrary. In a best-case scenario and as a valid way out, it depends on what we define $M_{\text {NEw }}$ to be.

Since constructionalization so defined gives rise to more issues than are strictly necessary, a suggestion could be that its definition as $F_{\mathrm{NEW}}-M_{\mathrm{NEW}}$ is analytically helpful if it refers to first attestations, that is, as the endpoint of changes in other constructions (Börjars et al. 2015; Flach 2020), which may give 'reanalysis' a distinct DCxG flavor. In any case, first empirical records are based on, and relative to, the analyst's subjective definition of $F-M$, which also defines $F_{\text {NEW }}-M_{\text {NEW }}$. Put differently, a definition of a construction is informed by our synchronic perspective and the construction's subsequent development. For instance, $F_{\mathrm{NEW}}-M_{\mathrm{NEW}}$ for the into-causative was defined as the first attestation of an unambiguous object-control structure, because this is how the construction

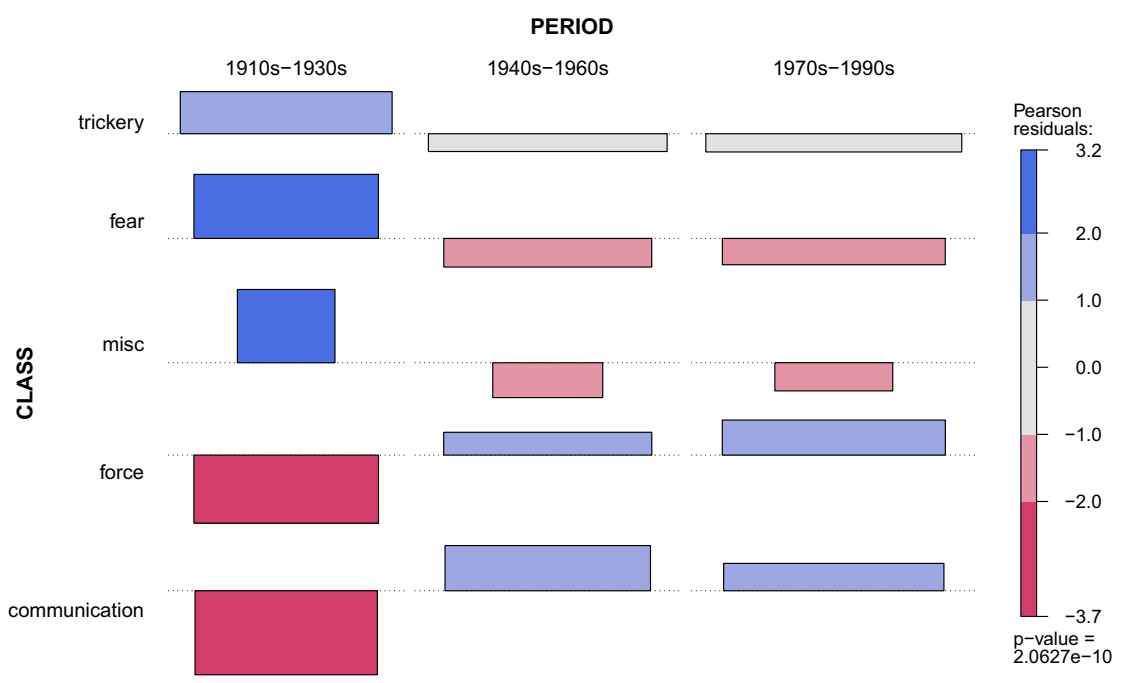

Figure 10: CLASS by PERIOD in the 20th century. 
was defined synchronically (he was honestly trepanned ... into giving sentence against himself, 1678, cf. (3) above). This definition is of course influenced by hindsight knowledge that the construction did become part of the constructional inventory of a substantial part of the speech community. Had it not passed a critical mass, we would likely have classified isolated tokens as idiolectal uses of the caused-motion construction or non-consequential flukes in the data (printing or production errors, non-native representations, etc.) and would probably never have posited it as a separate construction. In a sense, constructionalization is a matter of perspective from where change is investigated.

Hence, given the problems with distinguishing between pre-, con-, and postconstructionalization, it might be preferable to capture all changes surrounding $F_{\mathrm{NEW}}-M_{\mathrm{NEW}}$ as constructional changes that 'seize' any or multiple aspect(s) of a construction and/or its forerunner(s), including form(s), collocational preferences, semantics, co(n)text, distributional behavior, or communal spread (Hilpert 2013: 16). In other words, while constructionalization pertains to what we define a node to be or the perspective we take, constructional change tends to refer to what is observable in the data.

Node definition and its identification in historical data might be more straightforward for the into-causative compared to many other phenomena (especially those that are functionally far more polysemous). What is claimed here is that changes in nodes, networks, and links may be modeled as constructional changes without recourse to a distinct process of 'constructionalization'. Reducing constructionalization as a $F_{\mathrm{NEW}}-M_{\mathrm{NEW}}$ to the point when it is attested also avoids the unfortunate ambiguity of the term constructionalization which refers simultaneously to the point (new $F-M$ ) and the processes that necessarily surround or accompany its emergence (cf. Flach 2020). Ultimately, it may well be that a constructionalization view places more emphasis on the node, while the constructional change view puts more weight on connective or associative links. The latter remains relatively agnostic about the reality of nodes, instead viewing them as analytical helpful concepts. But it is for this reason that constructionalization is more vulnerable to terminological and empirical problems that tend to be avoided in a connective link view.

In this spirit, let us conclude with a reference to the growing body of constructionist approaches to vertical link changes within argument structure constructions (e.g., Colleman 2011; D’hoedt et al. 2019; Perek 2018), which complement the literature on changes between constructions, traditionally called 'alternations' (e.g., De Cuypere 2015; Wolk et al. 2013; Zehentner 2018). What we see is that many of these studies put greater emphasis on changes in links as dynamic re-configurations of the network of constructions (Torrent 2015). They shift the focus toward association-based conceptualizations of linguistic change 
that foreground the dynamicity of linguistic change. This perspective tends to be left behind in node-centered approaches (see Hilpert (2018b), Hilpert and Diessel (2016), and Schmid (2016) for discussion). This article attempted to contribute some further pointers how the shift away from node-centric definitions of change helps to shed new light on the dynamics of change.

Acknowledgments: The research was funded by the Swiss National Science Foundation (SNSF grant no. 100012L/169490/1, PI Martin Hilpert). I thank two anonymous reviewers, Martin Hilpert, Elena Smirnova, and Anatol Stefanowitsch for their helpful comments, constructive feedback, and food for thought. The usual disclaimers apply.

\section{Appendix}

\section{Classification of matrix verbs:}

COMMUNICATION/PERSUASION. argue, becoax, cajole, charm, cheer, chitchat, coax, convince, counsel, fast-talk, filibuster, flatter, hearten, heckle, impress, intrigue, invite, jive-talk, jolly, natter, overpersuade, persuade, please, romance, rouse, salestalk, scream, sign-talk, smooth-tongue, soft-soap, soothe, spur, stir, sweet-talk, talk, wheedle, woo.

FEAR/IRRITATION. aggravate, alarm, anger, annoy, astonish, awe, badger, bewilder, bewitch, boss, bother, bribe, browbeat, bully, challenge, chill, chivvy, conjure, cow, cry, curse, damn, daunt, dazzle, degrade, devil, distress, dog, educate, egg, embarrass, enrage, exasperate, exhort, fret, frighten, frustrate, gall, goad, guilt, harass, harry, hector, horrify, hound, humiliate, influence, insult, intimidate, irk, irritate, jar, jeer, josh, laugh, lie, lull, manipulate, nag, needle, nerve, nettle, nudge, overwhelm, panic, pester, pique, preach, provoke, psych, quiz, railroad, reason, ridicule, sadden, scald, scare, school, scold, scowl, shame, shellshock, shock, snow, spoil, spook, stampede, stare, startle, starve, sting, storm, stun, stupefy, surprise, sway, tease, terrify, terrorize, threaten, urge, victimize, wear, weary, witch, worry.

FORCE/PRESSURE. abuse, batter, beat, blackjack, blackmail, blow, bludgeon, bomb, bounce, brainwash, bulldoze, captivate, chase, coerce, compel, corner, corral, corrupt, cross-ruff, crowd, crush, cudgel, discipline, dope, dose, draft, drag, dragoon, draw, drug, elbow, flog, force, hammer, haul, henpeck, herd, high-pressure, hook, horsewhip, hurry, hustle, impact, impel, incite, intoxicate, jog, jostle, kick, kick-start, lasso, lock, maneuver, massage, maul, muscle, paralyze, peck, 
pinprick, poke, press, pressure, prick, prod, propel, pull, push, rope, rush, sandbag, scourge, shake, shred, shunt, slash, slave-drive, smash, snooker, squeeze, steamroll, steel, stiffen, strangle, strike, strong-arm, subdue, suck, sucker, suppress, sweep, thrash, thumbscrew, torment, torture, transfix, trap, trip, whip, whipsaw.

TRICKERY/DECEPTION. allure, attract, bait, bamboozle, befool, befuddle, beguile, bejuggle, betray, bluff, buffalo, cheat, con, confuse, cozen, deceive, decoy, delude, discombobulate, doctor, dupe, ensnare, entice, entrap, euchred, fake, fascinate, finagle, finess, flimflam, fool, fox, gammon, gull, hoax, hocuss, hoodwink, hornswoggled, humbug, hypnotize, inveigle, jockey, juggle, kid, lure, mesmerize, misconstrue, misguide, mislead, mystify, outwit, rook, screw, seduce, self-deceive, shanghai, sidetrack, spoof, swindle, tempt, trick, wangle, will.

MISCELLANEOUS. act, address, anesthetize, anglicize, back, bestir, blind, boink, brainstorm, buy, calm, careful, carry, catalyze, catapult, co-opt, coach, comfort, condition, construe, contrive, convert, cue, dare, deny, direct, drive, ease, enchant, entertain, excite, fan, fashion, fashionate, fatigue, form, freeze, galvanize, get, goose, groom, guide, huckster, induce, initiate, interest, jade, jolt, kiss, lead, lecture, legislate, lick, midwived, missionary, mistake, mobilize, mold, motivate, nurture, pat, peckay, pervert, plow, precipitate, program, project, rasp, rassle, rationalize, reeducate, regiment, scene, socialize, soften, sophisticate, sphroxify, spirit, spoon, steer, stimulate, subsidize, swing, systematize, tick, tickle, tinker, train, transmute, trigger, vamp, vote, wheel, work.

\section{References}

Barðdal, Jóhanna. 2008. Productivity: Evidence from case and argument structure in Icelandic. Amsterdam \& Philadelphia: John Benjamins.

Börjars, Kersti, Nigel Vincent \& George Walkden. 2015. On constructing a theory of grammatical change. Transactions of the Philological Society 113(3). 363-382.

Breban, Tine. 2014. What is secondary grammaticalization? Trying to see the wood for the trees in a confusion of interpretations. Folia Linguistica 48(2). 469-502.

Brunner, Thomas. 2019. Into-causatives in world Englishes. Paper presented at ICAME40, Université de Neuchâtel, June 2, 2019.

Colleman, Timothy. 2011. Ditransitive verbs and the ditransitive construction: A diachronic perspective. Zeitschrift für Anglistik und Amerikanistik 59(4). 387-410.

Croft, William. 2000. Explaining language change: An evolutionary approach. Harlow: Longman.

Davies, Mark. 2008. The corpus of contemporary American English: 450 million words, 1990present. (2015 offline version). Available at: https://www.english-corpora.org/coca/.

Davies, Mark. 2010. The corpus of historical American English: 400 million words, 1810-2009. Available at: https://www.english-corpora.org/coha/. 
Davies, Mark. 2012. The 400 million word corpus of historical American English (1810-2009). In Irén Hegedüs \& Alexandra Fodor (eds.), English historical linguistics 2010: Selected papers from the sixteenth international conference on english historical linguistics (ICEHL 16), 231-262. Amsterdam \& Philadelphia: John Benjamins.

Davies, Mark \& Jong-Bok Kim. 2019. Historical shifts with the into-causative construction in American English. Linguistics 57(1). 29-58.

De Cuypere, Ludovic. 2015. A multivariate analysis of the Old English ACC+DAT double object alternation. Corpus Linguistics and Linguistic Theory 11(2). 225-254.

De Smet, Hendrik, Susanne Flach, Jukka Tyrkkö \& Hans-Jürgen Diller. 2015. The corpus of Late Modern English (CLMET), version 3.1: Improved tokenization and linguistic annotation. FU Berlin, U Tampere, RU Bochum: KU Leuven.

De Smet, Hendrik. 2016. How gradual change progresses: The interaction between convention and innovation. Language Variation and Change 28(1). 83-102.

D’hoedt, Frauke, Hendrik De Smet \& Hubert Cuyckens. 2019. Constructions waxing and waning: A brief history of the zero-secondary predicate construction. Journal of English Linguistics 47(1). 3-28.

Duffley, Patrick J. 2018. Talk into vs convince to: Talking as a cause leading to containment, convincing as a cause leading to a result. In Mark Kaunisto, Mikko Höglund \& Paul Rickman (eds.), Changing structures: Studies in constructions and complementation, 15-30. Amsterdam \& Philadelphia: John Benjamins.

Flach, Susanne. 2018. "What's that passive doing in my argument structure construction?" A note on constructional interaction, verb classes and related issues. Paper presented the workshop Verb Classes, Frames, and Constructions, April 26-27, 2018. Mannheim: IDS.

Flach, Susanne. 2020. Constructionalization and the Sorites Paradox: The emergence of the intocausative. In Lotte Sommerer \& Elena Smirnova (eds.), Nodes and networks in Diachronic Construction Grammar. Amsterdam \& Philadelphia: John Benjamins.

Fonteyn, Lauren. 2017. The aggregate and the individual: Thoughts on what non-alternating authors reveal about linguistic alternations - a response to Petré. English Language and Linguistics 21(2). 251-262.

Fonteyn, Lauren. 2019. Categoriality in language change: The case of the English gerund. New York: Oxford University Press.

Friendly, Michael. 1992. Graphical methods for categorical data. In SAS User Group International Conference Proceedings, Vol. 17, 190-200.

Gilquin, Gaëtanelle. 2010. Corpus, cognition and causative constructions. Amsterdam \& Philadelphia: John Benjamins.

Goldberg, Adele E. 1995. Constructions: A Construction Grammar approach to argument structure. Chicago, IL: University of Chicago Press.

Gries, Stefan Th. \& Martin Hilpert. 2012. Variability-based neighbour clustering: A bottom-up approach to periodization in historical linguistics. In Terttu Nevalainen \& Elizabeth Closs Traugott (eds.), The Oxford handbook on the history of English, 134-144. Oxford: Oxford University Press.

Gries, Stefan Th. \& Anatol Stefanowitsch. 2004. Covarying collexemes in the into-causative. In Michel Achard \& Suzanne Kemmer (eds.), Language, culture, and mind, 225-236. Stanford, CA: CSLI.

Hilpert, Martin. 2013. Constructional change in English: Developments in allomorphy, word formation, and syntax. Cambridge: Cambridge University Press. 
Hilpert, Martin. 2015. From hand-carved to computer-based: Noun-participle compounding and the upward strengthening hypothesis. Cognitive Linguistics 26(1). 113-147.

Hilpert, Martin. 2018a. Wie viele Konstruktionen stecken in einem Wortbildungsmuster? Eine Problematisierung des Produktivitätsbegriffs aus konstruktionsgrammatischer Sicht. In Stefan Engelberg, Henning Lobin, Kathrin Steyer \& Sascha Wolfer (eds.), Wortschätze: Dynamik, Muster, Komplexität, 91-106. Berlin \& Boston: De Gruyter.

Hilpert, Martin. 2018b. Three open questions in Diachronic Construction Grammar. In Evie Coussé, Peter Andersson \& Joel Olofsson (eds.), Grammaticalization meets Construction Grammar, 21-39. Amsterdam \& Philadelphia: John Benjamins.

Hilpert, Martin \& Holger Diessel. 2016. Entrenchment in Construction Grammar. In Hans-Joerg Schmid (ed.), Entrenchment and the psychology of language learning: How we reorganize and adapt linguistic knowledge, 57-74. Berlin \& Boston: De Gruyter Mouton.

Hilpert, Martin \& Stefan Th. Gries. 2009. Assessing frequency changes in multistage diachronic corpora: Applications for historical corpus linguistics and the study of language acquisition. Literary and Linguistic Computing 24(4). 385-401.

Hopper, Paul. 1987. Emergent grammar. Berkeley Linguistics Society 13. 139-157.

Hopper, Paul J. \& Elizabeth Closs Traugott. 2003. Grammaticalization, 2nd edn. Cambridge: Cambridge University Press.

Hunston, Susan \& Gill Francis. 2000. Pattern grammar: A corpus-driven approach to the lexical grammar of English. Amsterdam \& Philadelphia: John Benjamins.

Kim, Jong-Bok \& Mark A. Davies. 2016. The into-causative construction in English: A constructionbased perspective. English Language and Linguistics 20(1). 55-83.

Mair, Christian. 2004. Corpus linguistics and grammaticalisation theory: Statistics, frequencies, and beyond. In Hans Lindquist \& Christian Mair (eds.), Studies in corpus linguistics, 121-150. Amsterdam \& Philadelphia: John Benjamins.

Perek, Florent. 2018. Recent change in the productivity and schematicity of the way-construction: A distributional semantic analysis. Corpus Linguistics and Linguistic Theory 14(1). 65-97.

Petré, Peter \& Freek Van de Velde. 2018. The real-time dynamics of the individual and the community in grammaticalization. Language 94(4). 867-901.

Rickman, Paul \& Mark Kaunisto. 2018. Aspects of the use of the transitive into -ing pattern in New Zealand English. In Mark Kaunisto, Mikko Höglund \& Rickman Paul (eds.), Changing structures: Studies in constructions and complementation, 71-87. Amsterdam \& Philadelphia: John Benjamins.

Rudanko, Juhani. 2000. Corpora and complementation: Tracing sentential complementation patterns of nouns, adjectives, and verbs over the last three centuries. Lanham, MD: University Press of America.

Rudanko, Juhani. 2005. Lexico-grammatical innovation in current British and American English: A case study on the transitive into -ing pattern with evidence from the Bank of English Corpus. Studia Neophilologica 77(2). 171-187.

Rudanko, Juhani. 2006. Emergent alternation in complement selection: The spread of the transitive into -ing construction in British and American English. Journal of English Linguistics 34(4). 312-331.

Rudanko, Juhani. 2011. Changes in complementation in British and American English: Corpusbased studies on non-finite complements in recent English. Basingstoke: Palgrave Macmillan. 
Hans-Jörg Schmid (ed.). 2016. A framework for understanding linguistic entrenchment and its psychological foundations. In: Entrenchment and the psychology of language learning: How we reorganize and adapt linguistic knowledge, 9-35. Berlin \& Boston: De Gruyter Mouton.

Smirnova, Elena, Robert Mailhammer \& Susanne Flach. 2019. The role of atypical constellations in the grammaticalization of German and English passives. Diachronica 36(3). 384-416.

Sommerer, Lotte \& Elena Smirnova (eds.). 2020 Nodes and networks in Diachronic Construction Grammar. Amsterdam \& Philadelphia: John Benjamins.

Stefanowitsch, Anatol. 2001. Constructing causation: A Construction Grammar approach to analytic causatives. Houston, TX: Rice University dissertation. http://hdl.handle.net/1911/ 18031.

Stefanowitsch, Anatol. 2014. Collostructional analysis: A case study of the English into-causative. In Thomas Herbst, Hans-Jörg Schmid \& Susen Faulhaber (eds.), Constructions collocations patterns, 217-238. Berlin \& Boston: De Gruyter.

Stefanowitsch, Anatol \& Stefan Th. Gries. 2003. Collostructions: Investigating the interaction of words and constructions. International Journal of Corpus Linguistics 8(2). 209-243.

Torrent, Tiago Timponi. 2015. The constructional convergence and the construction network reconfiguration hypotheses. In Jóhanna Barðdal, Elena Smirnova, Lotte Sommerer \& Spike Gildea (eds.), Diachronic Construction Grammar, 173-211. Amsterdam \& Philadelphia: John Benjamins.

Traugott, Elizabeth Closs \& Graeme Trousdale. 2013. Constructionalization and constructional changes. Oxford: Oxford University Press.

Wierzbicka, Anna. 1998. The semantics of English causative constructions in a universaltypological perspective. In Michael Tomasello (ed.), The new psychology of language: Cognitive and functional approaches to language structure, Vol. 1, 113-153. Mahwah, NJ: Lawrence Erlbaum.

Wolk, Christoph, Joan Bresnan, Anette Rosenbach \& Benedikt Szmrecsanyi. 2013. Dative and genitive variability in Late Modern English: Exploring cross-constructional variation and change. Diachronica 30(3). 382-419.

Wulff, Stefanie, Anatol Stefanowitsch \& Stefan Th. Gries. 2007. Brutal Brits and persuasive Americans: Variety-specific meaning construction in the into-causative. In Günter Radden, Klaus-Michael Köpcke, Thomas Berg \& Siemund Peter (eds.), Aspects of meaning construction in lexicon and grammar, 265-281. Amsterdam \& Philadelphia: John Benjamins.

Zehentner, Eva. 2018. Ditransitives in middle English: On semantic specialisation and the rise of the dative alternation. English Language and Linguistics 22(1). 149-175.

Zeileis, Achim, David Meyer \& Kurt Hornik. 2007. Residual-based shadings for visualizing (conditional) independence. Journal of Computational \& Graphical Statistics 16(3). 507-525. 